\title{
Mulemba
}

Revista Angolana de Ciências Sociais

6 (11) | 2016

Políticas, direitos e práticas da sociedade e do Estado

\section{A Política Externa Angolana: Doutrina e prática}

The Angolan Foreign Policy: Doctrine and Practice

\section{Miguel Domingos Bembe}

\section{(2) OpenEdition}

Journals

Edição electrónica

URL: https://journals.openedition.org/mulemba/1281

DOI: 10.4000/mulemba.1281

ISSN: 2520-0305

\section{Editora}

Edições Pedago

Edição impressa

Data de publição: 1 maio 2016

Paginação: 25-55

ISSN: 2182-6471

\section{Refêrencia eletrónica}

Miguel Domingos Bembe, «A Política Externa Angolana: Doutrina e prática», Mulemba [Online], 6 (11)।

2016, posto online no dia 01 outubro 2018, consultado o 21 setembro 2021. URL: http://

journals.openedition.org/mulemba/1281; DOI: https://doi.org/10.4000/mulemba.1281 


\title{
A Política Externa Angolana: Doutrina e prática*
}

\author{
Miguel Domingos Bembe ${ }^{* *}$
}

\begin{abstract}
Resumo: A Política Externa Angolana (PEA) é uma área quase desconhecida e ainda menos investigada. Como reflexo da capacidade do Estado na constante adaptação ao ambiente onde se insere, a Análise da Política Externa (APE) é crucial para tentar perceber as decisões e acções que os governos tomam - ou são obrigados a tomar - no sentido de preservar os aspectos positivos do ambiente internacional e explorar as eventualidades de alteração dos seus aspectos negativos. Este artigo, longe de querer colmatar a anunciada lacuna, pretende analisar e caracterizar, numa perspectiva analítica politológica e internacionalista, os momentos fundamentais da PEA, mais concretamente, as principais linhas de força e tendências da sua evolução desde 1975 até a actualidade. Deste modo, o processo da sua elaboração procurou corresponder à
\end{abstract}

* O presente artigo foi elaborado entre fins de Março e início de Abril de 2015, por convite do Observatório Político (op) do Departamento de Estudos Políticos (DEP) da Faculdade de Ciências Sociais e Humanas (FCSH) da Universidade Nova de Lisboa (UNL), que entendeu organizar uma obra com base, principalmente, no conjunto de comunicações proferidas na conferência Vizinhos Atlânticos: Angola e Brasil, realizada em 5 de Abril de 2013, em Lisboa, Portugal. Gostaríamos de expressar a nossa mais sincera gratidão aos organizadores, designadamente aos Professores Cristina Montalvão Sarmento, Bruno Bernardes e Gilberto Pereira. Os nossos agradecimentos são extensíveis ao colega Gilberto da Piedade Veríssimo pelas prestimosas críticas e sugestões e pelo incansável trabalho de revisão do texto final aprovado.

* Professor Auxiliar no Departamento de Ciência Política (DCP) da Faculdade de Ciências Sociais (FCS) da Universidade Agostinho Neto (UAN). Conselheiro do quadro de pessoal da carreira diplomática do Ministério das Relações Exteriores (MIREX), desempenhando as funções de Consultor no Gabinete do Ministro (GMRE), em Luanda, República de Angola. Investigador do Centro de Investigação em Análise de Políticas e Sistemas Eleitorais (CIAPSE/FCS-UAN), em Luanda e membro colaborador do Centro de Administração e Políticas Públicas (CAPP) do Instituto Superior de Ciêcias Sociais e Políticas (ISCSP) da Universidade de Lisboa (UL), em Lisboa, Portugal. 
necessidade básica e específica da adaptação expositiva a uma funcionalidade esquemática de abordagem, que não visa uma finalidade analítica aprofundada do intervalo temporal ao qual dedica uma atenção exclusiva.

Palavras-chave: Angola, política externa, transformações, tendências de evolução.

\section{Introdução}

Neste ambicioso e árduo exercício analítico, sempre incompleto, que visa sistematizar as principais linhas de força e tendências de evolução da Política Externa Angolana (PEA), julga-se imperioso começar por operacionalizar o conceito de Política Externa (PE) e apresentar, de forma sucinta, as diversas abordagens metodológicas e analíticas com bases epistemológicas específicas, que devem ser levadas em consideração na Análise de Política Externa (APE).

Na obra Elementos de análise de política externa, um dos acervos de IScsp, ${ }^{1}$ Víctor Marques dos Santos (2012), considera que a «política externa» corresponde a um «conjunto de processos, decisões e acções desenvolvidas pelos Estados, desempenhadas por órgãos próprios através da utilização de recursos e de instrumentos específicos». Trata-se, precisamente do «conjunto de linhas de acção política desenvolvidas fora das fronteiras territoriais de um Estado, e que têm como finalidade a defesa e a realização dos seus interesses, através da concretização dos objectivos definidos num programa de governo» (SANTOS 2000: 1). ${ }^{2}$

No plano académico, o estudo da política externa insere-se no objecto comum a várias disciplinas científicas das Ciências Sociais, designadamente da área da Ciência Política e das Relações Internacionais. São duas diferentes perspectivas de abordagem analítica de Política Externa que, no plano das Ciências Sociais, evidenciam uma transdisciplinaridade metodológica, cuja prática abarca tanto a Ciência Política como as Relações Internacionais, constituindo a sua complementaridade académica, um factor significativo em termos de progresso científico.

1 Instituto Superior de Ciências Sociais e Políticas (ISCSP) da Universidade de Lisboa (UL).

2 A diplomacia, por seu lado, constitui-se como «um instrumento da política externa, para o estabelecimento e desenvolvimento dos contactos pacíficos entre os governos de diferentes Estados, pelo emprego de intermediários, mutuamente reconhecidos pelas respectivas partes» (CALVET DE MAGALHÃES 2005: 92). 
Com efeito, numa visão politológica, «o estudo da política externa [...] situa-se no plano analítico comum às diversas políticas sectoriais do Estado e às inerentes interacções destas políticas. Através da política externa, os Estados estabelecem e desenvolvem as suas interacções relacionais». Na perspectiva internacionalista, «a Análise de Política Externa insere-se no âmbito do estudo de um ambiente relacional mais alargado, nomeadamente, dos sistemas de relações internacionais, a partir dos efeitos das acções de contacto desenvolvidas entre Estados, mas também entre estes $e$ os outros actores estatais e não-estatais da sociedade internacional» (SANTOS 2012). ${ }^{3}$ Todavia, "os Estados continuam a ser os principais actores porque são eles que promovem e desenvolvem as relações entre si, são eles que criam e suportam as organizações internacionais públicas e são eles que permitem que no seu interior sejam exercidas actividades por empresas ou firmas pertencentes a outros Estados. Por conseguinte, a intervenção dos Estados, através dos seus representantes, continua a influenciar o âmbito $e$ o carácter das relações internacionais» (FERNANDES 1998: 17; BESSA 2012: 35).

A permanência do actor Estado verifica-se, tanto no plano analítico politológico, partindo do próprio Estado através da interacção relaccional interno/externo/interno, como no plano analítico regional, internacional, ou global, partindo do sistema/ambiente através da dinâmica interactiva externo/interno/externo. Ao mesmo tempo, as características da intervenção processual do Estado, em termos de grau variável e de formas de agenciamento, evidenciam a alternância da centralidade do objecto em análise, variando entre o próprio actor Estado e o sistema/ambiente relacional em que se situa (SANTOS 2012).

No contexto desta análise, as coordenadas de base da Política Externa Angolana resultam em larga medida do facto de ser Angola uma «nação» africana, detentora de uma identidade histórica e cultural

3 Como refere António Fernandes, «as relações internacionais são o espelho das interacções desenvolvidas pelos principais actores internacionais - os Estados, as organizações internacionais e as empresas multinacionais e transnacionais -. Abrangem, portanto, as relações entre os Estados, as relações entre organizações internacionais e entre estas e os Estados, as relações entre os Estados e as empresas nacionais e multinacionais dependentes de outros Estados e as relações entre firmas e empresas sediadas em Estados diferentes» (FERNANDES 1998: 16). 
partilhada com nações vizinhas e com uma condição geoestratégica particular decorrente da sua maritimidade e da localização no cruzamento regional entre as Áfricas Central e Austral (BEMBE 2013a: 431-432). Aqueles factos obrigam que o país integre, em simultâneo, as organizações sub-regionais que aí se estabelecem, designadamente a Comunidade Económica dos Estados da África Central (CEEAC), ${ }^{4}$ a Comunidade para o Desenvolvimento da África Austral (SADC), ${ }^{5}$ a Comissão do Golfo da Guiné $(\mathrm{CGG})^{6}$ e a Conferência Internacional sobre a Região dos Grandes Lagos (CIRGL). ${ }^{7}$ Esta integração político-estratégica, aliada à "posição estratégica», ${ }^{\mathbf{8}}$ que o país assume naquele quadro sub-regional, confere-lhe a possibilidade

4 A CEEAC é constituída por 10 países: Angola, Burundi, Camarões, Gabão, Guiné--Equatorial, República Centro-Africana, República do Congo, República Democrática do Congo, São Tomé e Príncipe e Tchad. O Tratado constitutivo da CEEA foi assinado em Outubro de 1983 em Libreville, República do Gabão, e entrou em vigor em Dezembro de 1984.

5 A SADC, criada em 17 de Outubro de 1992, é constituída por 15 países: Angola, Botswana, Lesotho, Madagascar, Malawi, Maurícias, Moçambique, Namíbia, República da África do Sul, República Democrática do Congo, Seychelles, Swazilândia, Tanzânia, Zâmbia e Zimbabwe. A sADc, constitui hoje uma instituição regional de grande importância para o desenvolvimento económico coordenado na região, assim como para a estabilização política, tendo sido a sua antecessora, a Conferência para a Coordenação do Desenvolvimento da África Austral (SADCC), criada em 1980, em Lusaka, República da Zâmbia.

6 A CGG foi inicialmente idealizada em 19 de Novembro de 1999 e viria a ser fundada em 3 de Julho de 2001, em Libreville (Gabão), sendo constituída por 8 países: Angola, Camarões, Gabão, Guiné-Equatorial, Nigéria, República do Congo, República Democrático do Congo e São Tomé e Príncipe.

7 CIRGL é constituída por doze países: Angola, Burundi, Kenya, República Centro Africana, República do Congo, República Democrática do Congo, Rwanda, Sudão, Sudão do Sul, Tanzânia, Uganda e Zâmbia. Foi criada em 1994, após os conflitos políticos que marcaram esta região do continente africano e levaram ao reconhecimento da sua dimensão e a necessidade de um esforço conjugado para a promoção da paz e o desenvolvimento regional.

8 Entendida por Gilberto Veríssimo (2014) como «a atitude que o país assume, resultante da sua posição geográfica e posicionamento geoestratégico, observada a qualidade e especificidade das bases do poder nacional e os objectivos nacionais. A posição estratégica materializa-se através de Linhas de Força de Política Externa e de Defesa Nacional e determina o lugar e o papel que o país ocupa e desenvolve numa determinada região, considerando o sentido de alinhamento da conjuntura regional e internacional» (Veríssimo 2014: 69). Na sua obra Politische Geographie (Geografia Política), datada de 1897, Friedrich Ratzel (1844-1904), considera que a «Posição» (Lage) fornece as coordenadas de localização do Estado face aos outros, as suas referências geográficas, acidentes geográficos, fornecendo dados importantes sobre a sua insularidade e continentalidade. 
de integrar a sede do poder estratégico no mesmo e, consequentemente, acompanhar, de forma quase permanente, os mecanismos, processos, dinâmicas e tendências do desenvolvimento social, político, económico e cultural nos diversos Estados-membros.

Em rigor, a temática sobre o estudo da Política Externa Angolana, parece sugerir a necessidade de uma estrutura histórico-analítica multivectorial que, para a melhor percepção das principais linhas de força, da dinâmica e das tendências da sua evolução, abarcaria quatro períodos fundamentais.

Talvez fosse pertinente iniciar a análise nas décadas de 1950 e 1960, para abordar o processo de luta de libertação nacional e as preferências político-ideológicas explícitas da independência angolana (1950-1975).

Numa segunda fase, seria examinado o período compreendido entre 1975 e 1992, destacando os marcos da Política Externa de Angola pós-independente, o desmoronamento da União das Repúblicas Socialistas Soviéticas (URSs), e as mudanças político-ideológicas associadas, quer no plano interno angolano 9 como nos panoramas internacionais, ${ }^{\mathbf{1 0}}$ que, segundo Guedes (2011: 27), parece terem desencadeado uma reorientação sensível na política internacional do Estado angolano. Note-se que este período foi, infelizmente, marcado por guerras, primeiro a da independência e depois uma primeira fase de uma guerra civil muito dura, que contou com tropas estrangeiras dos dois lados, num quadro inevitavelmente matizado pelo ambiente bipolar do Sistema Político Internacional (SPI) vigente; um período que, em todo o caso, não é inteiramente unitário,

9 Em Angola, a Lei Constitucional n. ${ }^{\circ}$ 12/91, de 06 de Maio, aprofundada pela Lei de Revisão Constitucional de 1992, instaurou a democracia multipartidária; consagrou as garantias dos direitos e liberdades fundamentais dos cidadãos e o sistema da economia social de mercado. Estarão na base destas ocorrências, designadamente, a alteração do sistema de direcção centralizada da economia em 1985; a derrocada do sistema socialista em 1987; a assinatura dos Acordos de New York (Estados Unidos da América) em 22 de Novembro de 1988 e de Bicesse (Portugal) em 31 de Maio de 1991 (cf. BEmBE 2014: 98-99).

10 Desde Janeiro de 1989 o Leste Europeu foi arrebatado por fortes ventos de mudança. Os Governos comunistas deram lugar a regimes democráticos, que encetaram reformas económicas e reduziram as forças militares soviéticas nos países do Pacto de Varsóvia. A queda do Muro de Berlim (a 9 de Novembro de 1989) e a unificação alemã (a 3 de Outubro de 1990) marcaram o fim de um ciclo iniciado no final da Segunda Guerra Mundial. A queda do regime comunista levou à desintegração da uRss a 21 de Dezembro de 1991. Os países do báltico, Estónia, Letónia e Lituânia, foram os primeiros a anunciar a independência. 
pois se vê modulado em 1977, por profundas divergências internas no seio do Movimento Popular de Libertação de Angola (MPLA), o partido no poder; de novo em 1985, com o II Congresso do MPLA; e ainda em 1997, com o Saneamento Económico Financeiro (SEF), que em grande medida deu corpo às alterações económicas que se iriam seguir; para terminar com a realização de conversações que colocando frente a frente o Governo e as forças militares que se lhe opunham, trouxe ao país uma nova fase de intervenção político-social e relacionamento internacional.

A terceira fase reflectiria sobre o período pós-eleições de $1992,{ }^{11}$ que seguiu de perto a «terceira vaga» de democratizações no continente africano, e se viu marcado pelo reacender da guerra civil no país ${ }^{\mathbf{1 2}}$ e findaria no histórico 2002, ano do fim do conflito e do início da reconciliação nacional (1992-2002), ${ }^{13}$ incluindo o complexo processo de reconstrução do país levado a cabo, num quadro regional e global, pelo Presidente José Eduardo dos Santos e do Governo do MPLA, com destaque para as políticas que, a nível interno promoveram a reposição de municípios, a criação de uma estrutura administrativa, o reconhecimento das autoridades tradicionais, a projecção de forças policiais e militares no conjunto do território, ou seja, o monopólio de forças pelo Estado Angolano.

O quarto e último período compreenderia o processo de uma transição política mais concreta e menos nominal, a promoção e o reforço dos mecanismos nacionais de consolidação do processo democrático, bem como o alargamento e aprofundamento das relações multilaterais e das relações de amizade e de cooperação bilateral (2002 até à actualidade).

Contudo e embora se funde no empírico para delinear propensões, a nossa reflexão não se atém a análises de pormenor das tendências em muitos casos patentes, nem a grandes cogitações

11 Recordamos que em Setembro de 1992 foram realizadas as primeiras eleições em Angola.

12 Por rejeição dos resultados finais das eleições pela União Nacional para a Independência Total de Angola (UNITA) de Jonas Malheiro Savimbi (3 de Agosto de 1934 - 22 de Fevereiro de 2002).

13 Estendida em 2006 em Cabinda, onde foi assinado em 1 de Agosto de 2006, o Memorando de Entendimento para a Paz e Reconciliação na Província de Cabinda, entre o Governo angolano e o Forum Cabindês para o Diálogo (FCD), liderado pelo antigo líder da ex-FLEc/Renovada, António Bento Bembe. 
interpretativas - porventura dado os objectivos últimos do exercício não serem as de um cronista ou historiador. Tal como o fez Marques Guedes (2011), atemo-nos a pautar momentos conjunturais, e neles, a destrinçar as linhas de força estruturais mais marcantes e a projectar as tendências de evolução.

\section{A inevitabilidade da Política Externa}

Os múltiplos interesses que ligam os Estados entre si, como membros da comunidade internacional leva-os a conduzir actividades políticas externas, através do estabelecimento de contactos internacionais com vista à resolução de problemas ou à satisfação das necessidades de interesse comum ou recíproco. Esses contactos de concertação internacional (um dos conteúdos ou actos elementares da política externa) impulsionam o estabelecimento de relações de cooperação em diversos domínios como sejam de saúde, intercâmbio comercial e cultural, financeira e económica, emigração, científica e técnica, aliança militar, desportos, protecção de marcas e da propriedade intelectual. Tudo isto, naturalmente, para além das relações de carácter político e militar, mais ou menos intensas, consoante a participação em agrupamentos políticos dos Estados, a sua vizinhança geográfica, as suas afinidades ideológicas (CALVET DE MAGALHÃES 2001: 21 e 31; 2005: 26).

Deste modo, ter relações com outros Estados ou entidades internacionais é mesmo uma necessidade, porque desde cedo este tipo de sociedade política não pode viver no isolamento. As necessidades materiais da população apontaram para o estabelecimento de relações comerciais e as sociedades vizinhas colocavam problemas de viabilidade e segurança que os dirigentes políticos só poderiam resolver através de contactos directos e indirectos com outros centros de decisão. A guerra, as agressões, as disputas, as ameaças, tanto como a cooperação, perfilaram-se logo nos primeiros tempos da humanidade de modo que os chefes, mesmo dos pequenos grupos, tiveram desde logo que estabelecer relações de algum tipo com os vizinhos. E isto porque não era possível sobreviver sem ter contactos. Os custos de tal decisão acarretavam consequências e é preciso saber se os dirigentes e o povo estão preparados para as suportar (BESSA 2012: 70). 


\section{Os fins da Política Externa: Doutrina e prática}

Tendencialmente os dirigentes das sociedades políticas estaduais têm buscado constantemente certas metas que, no fundo, asseguram a sobrevivência da unidade política em causa - um interesse permanente que querem acautelar através de uma acção directa ou indirecta, em todos os quadrantes. Assim, a acção dos órgãos de Estado «cujo objectivo directo e imediato é a conservação da sociedade política, a definição e prossecução do interesse geral segundo as circunstâncias aconselharem, ou exigirem», referida como política nacional, traduz-se, na formulação de objectivos nacionais e na orientação concebida para a realização desses mesmos objectivos (Marcelo Caetano, apud CouTo 1988: 215).

Uma estrutura típica das sociedades desenvolvidas é a que toma em consideração a articulação de valores políticos de duas ordens distintas: socio-económicos, em que se incluem os correspondentes aos clássicos fins teleológicos ou a razão de Estado, ${ }^{14}$ a conservação/ segurança, a justiça e o bem-estar, e ético-jurídicos, como a dignidade, a liberdade e a igualdade (QueIROz 1994: 66).

Neste âmbito, com perseverança, com maior ou menor experiência, a materialização desse interesse toca em pelo menos, cinco objectivos tradicionais, claramente identificáveis, a saber (BESSA 2001: 86-103):

a) O objectivo da preservação do Estado na sua integridade, a que também se chama finalidade de segurança, é um tema sem fim,

14 Expressão usada pela primeira vez pelo autor florentino Francesco Guicciardini em 1526-1527, onde, justificando-se a política repressiva dos Medici, se assinala que o poder para vencer a contingência tem de recorrer à violência, não havendo poder legítimo. Consagra a expressão Giovanni Botero em Della Ragione di Stato, de 1583, considerando-se que os príncipes nas sua amizades e inimizades se regulam sobre aquilo que lhes proporciona vantagens. Arnold Clpamar utiliza a expressão arcana rerum publicarum, influenciado por Tácito que usa arcana imperri e arcana dominationis. Os franceses vão preferir as maximes d'État. Vários autores retomam o tema como Scipion Ammirato, Traiano Boccalini e Gabriel Naudé. Este último, em 1639, considera-a como tudo o que viola o direito comum em nome do interesse público. Carl J. Friedrich considera que a razão de Estado tem um perfil pré-constitucional, sendo uma situação limite, uma situação extraordinária, aproximando o conceito da perspectiva que Carl Schmitt adopta para o conceito de soberano, isto é, aquele que decide num estado de excepção. 
porque a segurança pode entender-se desde uma humilde, cautelosa, senão tímida posição de defesa até a atitude de defesa avançada e mesmo a de conquista de posições para melhor garantir a paz e tranquilidade na base material de poderio. Basicamente, o Estado busca manter a sua soberania sobre todo o território e defender-se adequadamente de qualquer ameaça, protegendo a sua população.

De facto, esta finalidade nunca está plenamente efectivada, porque se relaciona directamente com o estado de tensão ou equilíbrio da conjuntura e a que nenhum Estado, por muita força que possua, é imune. Entretanto, este objectivo parece ser primordial até porque a própria classe política dirigente pretende manter-se nas suas posições, mas isso depende da capacidade de resistir a uma outra, estrangeira, que a queira expulsar ou converter em mero instrumento administrativo da geografia dominada.

Normalmente os Estados asseguram este objectivo através de duas vias. Por um lado, mantendo forças dissuasoras credíveis, o que significa um poder militar conceituado no contexto político de referência, dimensionado portanto à sua geografia, ao seu Produto Interno Bruto e às responsabilidades assumidas nas organizações que integra. Por outro, estabelecendo alianças bilaterais com poderes amigos no sentido da cooperação e defesa mútua ou instituindo pactos multilaterais no seio de Organizações, que oferecem garantias de defesa e integridade terriorial a todos os membros activos.

b) A dimensão económica é fundamental para o poder real do Estado, que por aqui tenta também obter segurança nos níveis adequados. As linhas de abastecimento de matérias-primas indispensáveis ou críticas para as economias industrializadas, a defesa e expansão de mercados para produtos manufacturados, a protecção do mercado interno, o enfrentamento das tentativas de controlo económico estrangeiro, a defesa da moeda e do investimento no exterior, a política de crescimento económico, as políticas alfandegárias, os subsídios à exploração e modernização. Pelo fim económico, o Estado procura proteger e apoiar os seus interesses económicos.

c) Os Estados estão certamente a procurar reforçar o seu poder ou, no mínimo, a sua influência política, quando se encarregam da defesa de outros povos, instalam bases militares no estrangeiro, enviam corpos de exército para áreas de crise, arrendam bases 
navais, oferecem armamento aos países amigos, deslocam quadros militares para o treino local e adestramento do pessoal militar de nações associadas, patrocinam e apoiam facções políticas em outras sociedades com meios financeiros, quadros técnicos e treino político e comparticipam financeiramente no funcionamento de Institutos Políticos e Academias, que divulgam ideias, promovem debates e, publicam obras que afectam os intelectuais e as redes universitárias.

Esta função política é muito comum e vê-se um pouco por toda a parte, não raro associada a eufemisticamente chamada ajuda humanitária, mas também às políticas de apoio ao desenvolvimento ou de cooperação e ajuda. Trata-se de formas mais ténues de dependência política recorridas actualmente através de dependência económica, da dependência tecnológica, enfim da fragilidade político-militar do Estado e, a exploração dessas debilidades estruturais não se deixará de fazer pelos poderes atentos à conjuntura e sua evolução.

d) A língua, as realizações históricas, a arte, a moda, a tecnologia de um país, são dadas a conhecer por processos bem caros, mas criam um mercado e sobretudo assentam uma influência imaterial difusa que se revela a médio prazo muito útil para fins económicos e políticos. Trata-se do envolvimento na política de projecção cultural, de forma realista ou por motivos ideológicos para garantir a influência cultural.

A política cultural para o exterior é sempre uma política cara e de resultados a longo prazo, que interessa sobretudo aos grandes poderes como pano de fundo para estender a sua influência marcadamente política e económica. Os pequenos poderes sofrem o impacto desta ofensiva e mesmo as médias potências não escapam à persistente acção cultural da superpotência. Estratégias de defesa e de difusão da cultura própria podem então ser estudadas e delineadas.

e) O quinto objectivo dá corpo ao que antigamente se chamava propaganda e hoje se poderia designar como criação da imagem. Os países com imagem negativa encontram dificuldades de diversa ordem no clima de opinião pública mundial, que pode depois, num segundo tempo, pressionar os próprios governos, que dependem dos favores do voto popular, para tomar medidas restritivas contra eles. A propaganda inteligente torna-se um importante factor, não só para veicular a imagem adequada do Estado, como ainda para denegrir a imagem dos Estados adversários. 
O trabalho de marketing é, geralmente, coordenado por agências, departamentos ou gabinetes especializados e explora mais profundamente o filão de simpatias na opinião pública do país alvo, despejando sobre ele notícias, filmes, obras literárias e artísticas, escândalos, denúncias e todo um arsenal a que podem recorrer os serviços de inteligência ou «secretos» como fonte de dados susceptíveis de merecer «tratamento». Acção ocasional em certos países, acção permanente noutros, acção discreta em terceiros, cobre a escala destas actividades que, como se depreende, são apenas interessantes para poderes nacionais com projecto cultural na conjuntura.

\section{Os pilares da Política Externa Angolana}

Como escreve Bessa (2001), para defender os próprios interesses, económicos ou de qualquer outra natureza, quando em conflito com outros Estados, e também, em definitivo, para poder decidir autonomamente as questões internas, cada Estado deve prover antes de tudo à sua própria segurança, munindo-se do conveniente poder militar e desenvolvendo uma actividade diplomática que vise o equilíbrio da força da potência ou grupos de potências com as quais existem ou é preferível que existam divergências e conflitos.

Não há outra base real para uma política externa que não seja por um lado, o poder existente e disponível num espaço conhecido, que pode ser eventualmente projectado espacialmente à volta ou em qualquer ponto do mundo e, por outro, a conjuntura, que é a teia de poderes e objectivos das potências no momento. Deste modo, a avaliação de uma política externa pode ser feita pelos fins que busca materializar, embora possa perceber-se que as finalidades nem sempre se articulam. Neste quadro, a nova hierarquia de interesses e objectivos da política externa fará caminho para chegar aos pontos de execução e vai obrigar a redefinições graves dos caminhos percorridos até aí. Daí afirmar-se que as políticas externas são sempre um diálogo permanente entre um caminho velho e um caminho novo (BESSA 2001: 103-104).

O conceito da política externa proposto por Víctor Marques Santos (2000), ajustado ao contexto angolano, podemos afirmar que a Política Externa Angolana, corresponde ao conjunto de objectivos, estratégias e instrumentos que o Governo de Angola adopta e aplica 
à entidades fora da sua jurisdição política, para assegurar a defesa e materialização dos interesses nacionais. ${ }^{15}$ Como a observação empírica demonstrou, logo, após a proclamação da independência em 1975, o Governo angolano procurou que as capacidades nacionais que garantiam a sua legitimação internacional estivessem nas suas zonas de influência directa.

Evidentemente, a cultura estratégica de uma unidade política, subsidiária da sua localização geográfica, percurso histórico e cultura política das populações que nela habitam serve, em todos os instantes da sua vida, à definição do interesse nacional. ${ }^{\mathbf{1 6}}$ Este último, que resulta sempre de decisões políticas das entidades relevantes para o efeito, representando as vozes mais influentes daquela, umas vezes manifesta-se de forma tácita e outras vezes explícita.

Na definição do interesse nacional, o princípio de inclusividade aconselha que o interesse deve poder ser imputado a toda a Nação ou pelo menos a grande parte dela de modo à superar os interesses de facção ou de grupo. Esta posição não remete para qualquer conexão com a realidade conhecida pelo investigador porque essa ligação pura e simplesmente não existe. Tem um interesse prático no plano político, mas a sua defesa no plano teórico não remete para um neutralismo porque resumir o interesse nacional à política praticada de facto não é angelismo. O princípio de exclusividade sugere que a definição do interesse nacional não, leva em linha de

15 Ver ainda o conceito operatório de José Calvet de Magalhães (2005). Para o autor, a política externa contrapõe-se à política interna e, neste sentido, refere-se à actividade exercida por um Estado no domínio externo, ou seja, para além das suas fronteiras políticas. Trata-se do conjunto das decisões e acções de um Estado em relação ao domínio externo que se destina a obter um determinado resultado em relação a outro Estado ou grupo de Estados (CALVET DE MAGAlhães 2005: 22-23).

16 Segundo Colin Gray, «a cultura estratégica corresponde ao conjunto de modos de pensamento e de acção respeitantes ao uso da força, os quais resultam da percepção da experiência histórica nacional e das aspirações nacionais». Acresce ainda que toda a acção de uma comunidade de segurança, se não constitui uma manifestação de cultura estratégica, é pelo menos expressão de um processo em que os indivíduos são enculturados, e as organizações, os procedimentos e a gestão militar, são resultados de factores culturais permanentes (GRAY 1986: 36; 1994). Outro autor, Ken Booth (1990:121), entende que a cultura estratégica constitui um conjunto de tradições, valores, atitudes e símbolos, respeitantes à forma como as culturas percepcionam uma ameaça à sua segurança e como entendem a resposta pela força a essa ameaça. Booth considera que a cultura estratégica é persistente ao longo dos tempos, mas tal não significa que não evolua, tendo em conta factores de política interna e o ambiente internacional. 
conta os interesse de outras colectividades políticas exteriores ao país e só lhe presta atenção na medida em que podem vir a ter efeito nos interesses domésticos. Parte-se de uma predefinição do interesse nacional permanente em termos teórico-históricos de realismo político, com destaque para questões de segurança, para cuja salvaguarda é indispensável um adequado poder militar. Finalmente, o princípio de relevância externa considera que os interesses que compõem o interesse nacional devem poder ser afectados significativamente pela conjuntura internacional e, consequentemente, pela direcção da política externa do Estado. Trata-se de uma posição designada por enumerativa, preocupada em enumerar um núcleo básico de interesses fundamentais, fixando-se um número limitado de fins para os quais exista grande consenso e o problema dos limiares ou a definição momentum de perigosidade para a nação (segurança nacional em termos de segurança física, a integridade da ordem normativa, a prosperidade económica, propriedade, liberdade, prestígio, engrandecimento nacional. Assim, quando a ameaça é modesta não envolve o interessa nacional (BESSA 2001: 107-112).

Os princípios que sempre nortearam a Política Externa Angolana e as bases da sua projecção não fogem à linha doutrinária e a prática político-diplomática, já acima sistematizadas. Ao contrário de muitos Estados africanos para os quais o «universo exterior dos negócios estrangeiros», se resumia ao conjunto formado pelo excolonizador, as duas superpotências, os congéneres continentais e os seus vizinhos, Angola desde sua independência política de Portugal em 1975, sempre entreteve relações intensas com vários grupos de Estados (Clapham, apud Guedes 2011: 27).

Observam-se, por exemplo, as ligações, nomeadamente, com aqueles Estados de origem das empresas concessionárias e explorações petrolíferas no seu território - para além de, durante a $1 .^{\text {a }}$ República iniciada em 1975, ter cultivado relações estreitas com Estados ideologicamente afins, na maioria da Europa Central e de Leste e Cuba, e ainda com o Brasil, por motivos histórico-culturais complexos (Chabal, apud Guedes 2011, idem). A escala e a riqueza de Angola, bem como a sua importância geoestratégica no mundo bipolar, justificavam essa vasta e tão atípica gama de relações bilaterais. Naquele contexto estratégico, a ameaça de desmembramento do território e até mesmo de destruição do novo poder instituído conduziu a que, especialmente, a ligação bilateral da então República Popular de Angola com a malograda uRss se pautasse pela 
crescentemente intensificação de fluxos de apoios ao nível de segurança e defesa, à par do relativo à construção do novo país, designadamente no campo da formação de quadros. Para além do aconselhamento militar no terreno, a URSs viabilizou - tanto de um ponto de vista logístico como a nível político, pelo exercício do seu direito de veto no Conselho de Segurança das Nações Unidas - a presença no território angolano de contingentes de tropas cubanas; Moscovo fê-lo, de início, de maneira indirecta e cautelosa.

Enquanto país do Terceiro Mundo, ${ }^{17} \mathrm{Cuba}$ tinha mais e melhores razões do que a URSS para invocar solidariedade com África, em especial com Angola. Por outro lado, a presença dos cubanos seria mais aceitável para a Organização da Unidade Africana (OUA) e para Angola do que a dos soviéticos. Para além de Havana se dispôr de pessoal qualificado para manejar armas sofisticadas de fabrico soviético, os cubanos tinham maior facilidade de compreensão da língua portuguesa e de adaptação às adversas condições de vida de Angola e eram também, por serem «especialistas» em assuntos africanos. Em 1974, em matéria de África, Cuba tinha inquestionavelmente um conhecimento mais profundo do terreno, contactos mais constantes e solidariedades mais afirmadas que a União Soviética (SILVA 2012: 84-86). Contudo, se a decisão de enviar tropas a Angola e todo o planeamento da operação teve início em Havana, o consentimento de Moscovo era essencial por suportarem a totalidade da missão.

A participação militar cubana em Angola começou cedo, ainda antes da independência. Na década seguinte vir-se-ia a intensificar com o agravar do conflito. Com efeito, em Novembro de 1987, ante a persistente e cada vez mais profunda no território e perigosa agressão do então regime racista sul-africano, Cuba decidiu incrementar a defesa militar da República Popular de Angola. Deste modo, o assalto de maior envergadura contra a localidade de Kwitu-Kwanavale, na província do Kwandu-Kuvangu, lançado em 23 de Março de 1988 pelos sul-africanos, foi travado abrupta e definitivamente pelas forças conjuntas cubano-angolanas. A estrondosa derrota

17 A expressão surgiu na época da Guerra Fria para designar os países que não estavam nem do lado dos EUA nem do lado da URSs, os chamados «não-alinhados». Esta expressão foi utilizada pela primeira vez pelo demógrafo francês Alfred Sauvy, mas encontra-se hoje em desuso, preferindo apelidá-los de países em desenvolvimento. 
do exército da África do Sul que secundarizava a UNITA no Kwitu--Kwanavale, e a possibilidade de se ver derrotada no território da Namíbia pelo avanço das forças das FAPLA ${ }^{18}$ e das FAR, ${ }^{19}$ forçou a alteração da estratégia do ocidente e do regime do apartheid, que optou por negociar o fim do seu envolvimento militar directo no conflito angolano.

Com efeito, depois da histórica campanha militar (1987-1988), considerada a mais prolongada no continente africano desde a Segunda Guerra Mundial (1939-1945), a correlação de forças na região da África austral transfigurou-se e o que era o mito da invencibilidade dos sul-africanos, tornou-se ponto de viragem decisivo na guerra que se arrastava há anos. A Batalha do Kwitu-Kwanavale, centrada em território angolano, teve repercussões também políticas no regime do Apartheid. A superioridade demonstrada pelas FAPLA levaram a África do Sul a aceitar a assinatura de um acordo tripartido com os governos de Angola e de Cuba em Dezembro de 1988, em New York, sob os auspícios das Nações Unidas.

A assinatura do Acordo de New York deu origem à cessação das hostilidades militares entre Angola e a África do Sul; a implementação da Resolução 435/78, de 29 de Setembro do Conselho de Segurança das Nações Unidas, sobre a ocupação ilegal da Namíbia pela África do Sul desde 1915 e o seu direito à autodeterminação, concretizada em 21 de Março de 1990, sob a supervisão da onU; e ao fim do regime de segregação racial na África do Sul, instituído em 1944.

De igual modo, na sequência dos Acordos de New York de Dezembro de 1988, a Resolução 626/88, de 20 de Dezembro do Conselho de Segurança da onu, estabeleceu a primeira Missão de Verificação das Nações Unidas em Angola (UNAVEM I), com o objectivo de monitorizar a retirada dos 50 mil soldados cubanos do território angolano e das forças sul-africanas que ocupavam ilegalmente parte do sul do território de Angola desde 1982. Trata-se de «um acordo internacional que não procurou resolveu a dimensão interna do conflito angolano e nem recomendou o fim das intervenções estrangeiras» (PUREZA 2007: 7).

\footnotetext{
18 Forças Armadas Populares de Libertação de Angola do Governo da República de Angola.

19 Forças Armadas Revolucionárias de Cuba.
} 
Como os poderes evoluem ao longo do tempo, desaparecendo, esfumando-se, afirmando-se, decaindo, retraindo-se nas suas esferas internas ou intervindo activamente, atacados pela febre de fazer uma política mundial, as conjunturas modificam-se substancialmente. Em Angola, a emergência de uma nova ordem internacional, a partir do final dos anos 1980 e, sobretudo, durante os anos 1990, impulsionou o governo do MPLA a adoptar uma estratégia da abertura política gradual, na medida em que tal abertura não alterasse, no essencial, a sua manutenção como principal força condutora do país (BEMBE 2014: 98).

Neste período pós-bipolar, o da chamada $2 .^{a}$ República, o multidimensionamento crescente dos palcos internacionais determinou o sentido dos realinhamentos realizados no país, com destaque para a organização do poder do Estado e a alteração do sistema de direcção centralizada da economia em 1985.

Com efeito, a nova ordem internacional em gestação, desencadeou igualmente a reorientação na política internacional de Angola, tornando-a cada vez mais multilateral. Nesta altura, salienta-se também a progressiva entrada em cena, de numerosos actores não-estatais no universo exterior da política externa angolana. O ponto focal tendeu a ser a prestação de ajudas de emergência - reconfiguradas por um novo contexto internacional e global que permitiu uma sua reinterpretação local (GuEDES 2011: 28; BEMBE 2013a: 441).

Fica, então, evidente que um dos mais importantes eixos de ligações multilaterais do Estado angolano tem sido constituído por aquelas mantidas, por um lado, com a OUA (UA, desde 2002) e, por outro, as entretidas com organizações regionais subsidiariamente mais próximas, e pragmática e organizacionalmente mais adequadas aos interesses dos angolanos. Face à vitória efectiva do MPLA, ${ }^{\mathbf{2 0}}$ sobre os seus adversários, ${ }^{21}$ em 11 de Novembro de 1975, a ouA decidiu apoiar este, quando alguns Estados-membros estavam divididos em alianças com outros movimentos angolanos que passaram à clandestinidade (Birmingham, apud GuEDES, op. cit.: 31).

A divisão entre os Estados-membros da oua no que se referia a Angola não lhe permitiu realizar pressões eficazes que assegurassem

\footnotetext{
20 Movimento Popular de Libertação de Angola (fundado em 1956).

21 Especialmente, a Frente Nacional de Libertação de Angola (FNLA) e a União Nacional para a Independência Total de Angola (UNITA).
} 
quer o controlo efectivo, pelo Governo angolano, da totalidade do território nacional, quer a integração das demais forças políticas na governação do recentemente nascido Estado Angolano. As capacidades da organização foram igualmente muito limitadas para ajudar a superar a situação de desastre alimentar, refugiados e conflitos internos - três dos maiores problemas que afligiram Angola, de 1975 à 2002. Contudo, a ouA teve pouca importância na contestação de relações externas do Estado e não se opôs directamente à presença de tropas cubanas no continente. Ainda pelo contrário, concedeu invariável solidariedade moral ao Governo angolano quando este se via confrontado com sucessivas incursões sul-africanas em território nacional soberano.

Perante a ineficácia da ouA, outras organizações, nomeadamente regionais, viriam localmente sobrepor-se-lhe, a mais importante das quais foi a SADCC (SADC, desde 1992), criada em Lusaka (Zâmbia), em 01 de Abril de 1980, para fazer frente ao regime de apartheid sul-africano (1944-1990). ${ }^{22}$ Desde o início, Angola teve um papel central nesta organização, no plano político-estratégico geral e, a nível técnico-logístico, no sector particularmente das políticas de energia. Apesar das diversas mutações de cenário internacional, regional e nacional, as relações entre Angola e SADC continuam a ser uma das prioridades da política externa de Luanda e o país mantém a sua posição de privilégio nesta organização sub-regional.

Fica, evidente, que as principais potências intervenientes despenharam sempre, em Angola, na duplicidade de registos entre a actuação no quadro da onU e a afirmação dos seus interesses e interlocuções privilegiados. Esta duplicidade, pode talvez, explicar o repetido insucesso que marcaram os esforços da comunidade internacional, através das Nações Unidas, não conseguir conduzir uma paz sustentável e duradoura e foram repletos de complexidade e controvérsia. Com efeito, e talvez compreensivelmente, as potências regionais e internacionais estrangeiras que instrumentalizaram as tensões internas existentes em Angola tenderam sempre a centrar as suas decisões nos seus próprios interesses nacionais, e não nos dos angolanos.

$\mathbf{2 2}$ Termo africâner que quer dizer separação, surgiu oficialmente na África do Sul em 1944, e serve para designar a política de segregação racial e de organização territorial aplicada de forma sistemática naquele país, durou até 1990 (cf. Apartheid, disponível na Internet: < http://www.infoescola.com/historia/apartheid>, consultado em 29 de Março de 2015, às 23:08:50). 
Como escreve Pureza (2007: 4 e 6), se os vários acordos de paz assinados foram desenhados para colocar um fim a uma guerra sangrenta e prolongada, a verdade é que não representaram uma análise ou tentativa de resolução dos principais problemas internos. A guerra civil angolana envolveu não só questões políticas de grande importância, mas também e principalmente profundos interesses económicos, devido aos seus imensos recursos naturais, em particular o petróleo e os diamantes.

A falta de consenso sobre o modo como a riqueza de Angola deveria ser dividida num momento pós-conflito «armadilhou», em última análise, as bases do processo das operações de paz. A ineficácia destas operações das Nações Unidas em Angola prendeu-se também com o baixo nível de compromisso internacional e de recursos mobilizados, o que se traduziu em mandatos que não permitiam que a onu se tornasse um actor central no processo de implementação dos acordos de paz. O Governo de Angola procurou, assim, responder a um contexto de guerra civil, que vigorava desde que $o$ país alcançou a independência, em 1975, principalmente, contra os então rebeldes da UNITA. Como atrás ficou sublinhado, o conflito estava adicionalmente inscrito no palco do confronto bipolar, com apoio e interferência dos EUA e da África do Sul à UNITA, enquanto o Governo angolano era apoiado pela então uRss e Cuba. De par com as suas ligações com a União Africana, ${ }^{23} \mathrm{o}$ Governo de Angola manteve até 2002 - e mantêm-na ainda hoje em dia, relações mais intensas com outras entidades sub-regionais e vários dos organismos e agências especializadas da oNu. ${ }^{24}$

23 A União Africana (UA) foi criada a 11 de Julho de 2000 para substituir a Organização da Unidade Africana (ouA), fundada a 25 de Maio de 1963, em Addis Abeba (Etiópia). O projecto foi lançado, em 1999, em Sirte (Líbia), pelo líder líbio Muhammar Khadaffi (1969-2011), que incentivou a criação da instituição, com base no modelo da União Europeia e do Acordo de Comércio Livre da América do Norte (NAFTA). Em Julho de 2000, em Lomé (Togo), foi adoptado o Acto Constitutivo da uA e, em Julho de 2001, em Lusaka (Zâmbia), foi estabelecido o programa de substituição da ouA pela UA. Em 2002, na Cimeira de Durban (África do Sul) procedeu-se à sessão inaugural da Conferência dos Chefes de Estado e do Governo da instituição (cf. União Africana, disponível na Internet: <http:// www.infopedia.pt/\$uniao-africana>, consultado em 28 de Março de 2015, às 22:08:46).

24 Angola foi reeleita Membro Não Permanente do Conselho de Segurança das Nações Unidas (CS-NU) para o período de 2015-2016, depois de ter cumprido o primeiro mandato no biénio 2003-2004, um ano após a assinatura do acordo de paz com a UNITA. 


\section{A nova estratégia da Política Externa Angolana}

\section{O binómio segurança/desenvolvimento}

Como já atrás ficou aflorado, em política externa, os principais interesses de que o Estado é responsável são os que implicam a sobrevivência da nação, mas logo em seguida, vem a satisfação e a protecção dos seus interesses económicos (Raymond Aron, apud FRANCISCO 2013: 110).

A síntese do percurso histórico e político-diplomático, exposto no ponto anterior, evidencia com clareza, que a postura estratégica nacional deu uma primeira indicação sobre o caminho a ser seguido para a definição dos objectivos nacionais permanentes desejados. $\mathrm{O}$ caminho definido permitiu à condução dos esforços necessários para a concretização daqueles objectivos que requerem o emprego da força militar, porque corresponde à maneira mais adequada de alcançar os propósitos do país, tendo presente os resultados da apreciação das situações internacional e nacional. Trata-se da necessidade de manter Angola numa posição favorável de tal forma que sejam difícil os seus contendores provocar-lhe prejuízos inaceitáveis.

Deste modo, através da sua política interna, sustentada pela actividade política externa, o Governo de Angola tem procurado materializar os objectivos teleológicos do Estado, consubstancializados na consolidação da nação e da independência nacional; na salvaguarda da integridade territorial; no reforço da unidade nacional; na defesa da soberania nacional e da democracia; e, na protecção das liberdades fundamentais e dos direitos da pessoa humana, mesmo durante o prolongado período da guerra (1975-2002).

O novo ambiente político nacional proporcionou as condições necessárias para a recuperação e o desenvolvimento de infra-estruturas várias sustentado, sobretudo, nas parcerias externas. A conjuntura internacional e nacional obrigou também Angola a redefinir prioridades para a afirmação de uma Política Externa mais activa e pragmática, a nível multilateral e bilateral.

Deste modo, hoje, em dia, a actuação político-diplomática de Angola parece priorizar questões relacionadas com a segurança e o desenvolvimento. Este binómio «segurança/desenvolvimento» a nível regional, tende a ser o eixo principal da Política Externa Angolana, designadamente na CEEAC, SADC, CGG E CIRGL, ao mesmo 
tempo que o país procura fazer sentir o seu peso nos grandes assuntos internacionais através das Nações Unidas. A investigadora angolana Aida Pegado ${ }^{\mathbf{2 5}}$ aprofunda esta matéria de forma fascinante na sua tese de doutoramento em Estudos africanos (PEgAdo 2013: 188-190, 197-199).

No plano internacional, continental e regional, Angola tem vindo a promover o reforço e alargamento das relações multilaterais, especialmente, nas Nações Unidas, nas Zona de Paz e Cooperação do Atlântico Sul (ZOPACAS), na UA, CEEAC, SADC, $\mathrm{CGG}^{\mathbf{2 6}}$ CIRGL, nos Países Africanos de Língua Oficial Portuguesa (PALOP) ${ }^{27}$ e na Comunidade dos Países de Língua Portuguesa (CPLP). ${ }^{\mathbf{2 8}}$

No quadro específico da Comissão do Golfo da Guiné (CGG), o Brigadeiro angolano Gilberto Veríssimo (2014: 13), aprecia na sua tese de doutoramento em Estudos Estratégicos, defendida no Iscsp, em 31 de Outubro de 2014, a posição estratégica de Angola na região, isto é, o papel que lhe é possível desempenhar para que possa ocorrer o desenvolvimento harmonioso da mesma num quadro de paz e segurança. Para o efeito, aventa como se enquadra nos objectivos nacionais actuais a intenção de transformar a região em zona de paz e segurança. De igual modo faz a interacção dos cenários internacional, continental e regional com as Bases do Poder do país, ${ }^{\mathbf{2 9}}$ para determinar os Objectivos Nacionais Actuais no âmbito da região e conclui sobre os conceitos estratégicos de relações externas

25 Defendida no IscTe/IuL, em Lisboa, Portugal.

26 A sexta parte da tese de doutoramento em Estudos Estratégicos apresentada por Gilberto Veríssimo, esclarece a posição estratégica da República de Angola na região, isto é, o papel que lhe é possível desempenhar para que possa ocorrer o desenvolvimento harmonioso da mesma num quadro de paz e segurança. Nesta parte, o autor aprecia como essa posição estratégica se enquadra nos objectivos nacionais actuais com a intenção de transformar a região em zona de paz e segurança; e faz a interacção dos cenários regional, continental e internacional com as bases do poder do país, para determinar os objectivos nacionais actuais no âmbito da região e concluir sobre os conceitos estratégicos de relações externas e de defesa de Angola, que se materializam através de linhas de forças de política externa e de defesa nacional que enformam as políticas externa e de defesa nacional para a região (VERíssimo 2014: 283-335).

27 Constituído por Angola, Cabo Verde, Guiné-Bissau, Moçambique e São Tomé e Príncipe.

28 Integra Angola, Brasil, Cabo Verde, Guiné-Bissau, Moçambique, Portugal, São Tomé e Príncipe e Timor Leste.

29 É o resultado da aplicação do potencial estratégico do país. Manifesta-se através dos seus índices de desenvolvimento e da riqueza tangível e intangível que ele gera (VERÍSSIMO 2014: 215). 
e de defesa de Angola, que se materializam através de Linhas de Forças de Política Externa e de Defesa Nacional que enformam as políticas externa e de defesa nacional para a região.

De facto, restaurada a paz, Angola se posicionou de maneira dinâmica e marcante na arena internacional, regional e na vizinhança imediata e engaja-se, a cada dia, de forma persistente na resolução das crises na sub-região, transformando-se num país exportador de paz, segurança, estabilidade e desenvolvimento (BЕмвE 2013a: 441; 2014: 175 e 180). Atesta este dinamismo, o constante empenho e dedicação do Governo angolano nos esforços de paz, estabilidade e desenvolvimento no Leste da República Democrática do Congo (RDC), na República Centro-Africana (RCA) e no Sudão do Sul, tendo como fundamentos a larga experiência acumulada pelo país na resolução pacífica de conflitos, em especial na África Austral, e a capacidade de fomentar relações de confiança e consensos, bem como o clima de paz, diálogo e reconciliação entre partes.

Nos últimos anos, Angola tem granjeado respeito e confiança dos parceiros internacionais e regionais. Deste prestígio, em 16 de Outubro de 2014, os 193 membros da Assembleia Geral da onU, reelegeram Angola com 190 votos, como Membro Não Permanente do Conselho de Segurança das Nações Unidas (CS-NU) para o período de 2015-2016, depois de ter cumprido o primeiro mandato no biénio 2003-2004, um ano após a assinatura do acordo de paz com a UNITA, que colocou fim aos 26 anos de guerra civil ${ }^{30}$. Nesta eleição, a Diplomacia angolana garantiu não apenas o apoio da União Africana, mas também da China e da Rússia (Membros Permanentes do Conselho de Segurança ao lado dos EuA, da França e da Inglaterra) e da Comunidade de Países de Língua Portuguesa (CPLP). Angola preside igualmente a Conferência Internacional da Região dos Grandes Lagos (CIRGL), para um mandato de dois anos (2014-2015); o Processo Kimberley ${ }^{\mathbf{3}}$ para o ano de 2015 e o FORUM PALOP - Fórum dos

$\mathbf{3 0}^{\mathbf{O}} \mathrm{O}$ cs tem uma particular relevância, em relação à África, designadamente ao papel que desempenha na aprovação do envio de missões de paz para cenários de conflito, como são os casos da República Centro Africana e do Sudão do Sul, bem como o debate de um dos temas que preocupam as Nações Unidas, como a propagação do vírus do ébola, cujo foco inicial foi a África ocidental, a Libéria, a Guiné Conacri, entre outros.

${ }^{31}$ Trata-se de um processo que visa certificar a origem dos diamantes, a fim de evitar a compra de pedras originárias de áreas de conflito. Foi criado em 2003 com o objectivo de evitar o financiamento de armas em países africanos em 
Países Africanos de Língua Oficial Portuguesa (2014-2016), desde a Cimeira Constitutiva, realizada em Luanda, em 30 de Junho de 2014.

No âmbito bilateral, Angola tem vindo a fortalecer e aprofundar as relações de amizade e de cooperação com os países africanos, europeus, americanos, asiáticos e da Oceânia, com benefícios recíprocos.

Assim, no seu discurso proferido, em Paris, em 29 de Abril de 2014, o Presidente angolano, José Eduardo dos Santos, considerou de suma importância que os investidores estrangeiros estabeleçam com investidores angolanos verdadeiras parcerias com benefícios recíprocos, envolvendo, além da aplicação de capitais, transferências de conhecimentos, tecnologias e cruzamentos de participação. O governo angolano, quer contar, também, com a capacidade e recursos dos investidores estrangeiros, para ajudar a diversificar e industrializar ainda mais a economia nacional e combater as assimetrias regionais, o desemprego e a baixa qualificação técnica e profissional. Deste modo, o alargamento da cooperação bilateral com alguns países torna-se inevitável para o exercício da actividade económica nos sectores primário e secundário. Angola tem também executado com sucesso o seu programa de reformas económicas, que assenta em dois pilares fundamentais. Por um lado, a consolidação da estabilidade macroeconómica, com destaque para o controlo da inflação e por outro, um ambicioso programa de investimento público de reabilitação, modernização e expansão das infra-estruturas no domínio da educação, saúde, habitação social, saneamento básico, transportes rodoviários, ferroviários, dos portos, aeroportos, da energia e águas (EDUARdo dos SANTOS 2014).

No contexto da promoção da imagem do país, o Chefe de Estado angolano, salientou que, além das potencialidades em recursos naturais, prevalece também em Angola «um clima favorável ao investimento e ao crescimento económico», sustentado pela paz e

guerra civil. Angola assumiu, pela primeira vez na história, a presidência do Processo Kimberley, na reunião plenária da organização realizada a 14 de Novembro de 2014, na cidade chinesa de Guangzhou. Até 2014, Angola desempenhava o cargo de Vice-Presidente e durante o seu mandato elegeu como prioridade garantir e proteger a produção e exportação de diamantes brutos produzidos no País até ao mercado mundial, cooperar na definição de métodos de prevenção e combate dos diamantes de conflito e tráfico ilícito, bem como o acompanhamento da evolução do mercado internacional de diamantes. 
estabilidade política e social, conquistada desde 2002, fundamental para gerar a confiança indispensável aos investidores e promover o desenvolvimento sustentável do país. ${ }^{32}$

\section{Para uma estratégia geopolítica angolana: modelo de elaboração}

Verifica-se que o conceito estratégico serve a prévia definição do interesse nacional. Se este estiver deficientemente definido ou não definido é preciso entender que pouco ou muito se pode fazer em matéria estratégica. E mesmo depois de definido o conceito, ainda que com o rigor gasoso que tais diligências atingem, torna-se necessário perguntar pelos meios que tornarão operacional (BESSA 2001: 105).

O planeamento e a execução de uma estratégia de afirmação geopolítica de Angola requerem o desenhar de um quadro analítico assente em vários factores de sustentação e projecção, internos e externos. A dissertação de Mestrado em Estratégia, defendida em 31 de Março de 2009, no IsCSP, dedica um ponto sobre «Paz, Segurança e Projecção de Angola», no qual incutimos a necessidade de um conceito estratégico nacional ajustado ao actual contexto pósconflito do país (BEMBE 2013a: 210 e 427-441).

Para o efeito, Heitor Romana (2012: 1-2) concebe e presenta um modelo que apelida por «Guidelines para uma estratégia geopolítica de Angola, nos planos regional e global». ${ }^{33} \mathrm{O}$ modelo proposto é composto por oito (8) itens fundamentais que passamos a caracterizar, com ligeiras adaptações consensuais fundamentados no nosso artigo, «Os vectores da construção da Nação Angolana e a função do Estado» (BEMBE 2013b: 167-183).

a) Doutrinários: É necessária a construção de uma orientação doutrinária estratégica, isto é, um conjunto de reflexões políticas,

32 Presidente da República [José Eduardo dos Santos] exorta empresários franceses a investirem em Angola (Disponível na Internet: <http://www.embaixadadeangola.pt/presidente-da-republica-exorta-empresarios-franceses-investirem-em-angola>, consultado em 4 de Abril de 2015, às 23:04:30).

33 Texto não publicado facultado pelo Professor Catedrático Heitor Barras Romana, Coordenador da Unidade de Estratégia, Coordenador da Escola de Estudos Políticos e Estratégicos do IscSP, da Universidade de Lisboa. 
diplomáticas e militares que sustentem o desenvolvimento do «destino geopolítico» de Angola. A orientação doutrinária poderá incidir sobre a natureza anfíbia da profundidade geostratégica de Angola - uma grande plataforma que penetra o heartland da África Subsariana e que em simultâneo se projecta da costa africana para o cone sul do Atlântico.

b) Identitários: Angola assume cada vez mais a condição de Estadonação plasmada numa ideia de «angolanidade» ${ }^{34}$ que gradualmente poderá esbater as distinções étnico-culturais e linguísticas que ainda perduram. Essa «angolanidade» constitui uma maisvalia estratégica face aos processos disruptivos infelizmente verificados em muita da África Subsahariana. É um factor de estabilidade que fortalece as posições de Angola face a outros Estados, designadamente a Nigéria, os Congos, e a África do Sul.

c) Cultura geopolítica: As elites políticas e intelectuais emergem como referências para uma percepção da posição que Angola tem no mundo e na região. Importa perceber como os outros Estados vêem Angola. A cultura geopolítica está fortemente associada ao «mito fundador» de Angola: O que distingue o país de outros Estados regionais? Quais as suas mais-valias no contexto geográfico, e político-militar? Tem uma cultura geopolítica proactiva ou defensiva?

d) Político-Institucionais: O modelo político-constitucional de matriz presidencialista e a sua configuração à volta da ideia de «um Presidente carismático, que gera um Estado forte», é, sem dúvida um factor determinante na afirmação geopolítica de Angola, nos planos regional e global. De facto, a estabilidade do regime de Luanda é gerador de um clima de confiança junto das lideranças africanas e mundiais e torna o Presidente num actor incontornável no sistema internacional, em termos bilaterais e multilaterais. A continuidade de um processo político sem sinais de anomia política e social dão credibilidade às posições da liderança política angolana.

e) Política Externa: A posição de Angola como estado-director na África Austral, a sua inserção na SADC, CEEAC, CGG, CIRGL, CPLP

34 Definimos «o conceito de angolanidade como um manifesto colectivo de convivência multiétnica e multirracial, no sentido de superar as contradições raciais e culturais, ao serviço da tolerância, da paz e sobretudo de unidade nacional» (BЕмBE: 2013b: 180; 2014: 130). 
e PALOP, a par da sua capacidade de influência na UA valorizam a condução de uma política externa multivectorial, isto é, uma leitura pragmática do equilíbrio dos poderes em África e nas relações Sul-Norte, a que se aditam os reajustamentos geoestratégicos ditados pela conjuntura e uma necessária aposta na diversificação de parcerias estratégicas em todos os continentes, através da diplomacia económica e da diplomacia de defesa.

f) Económicos. Os vastos recursos energéticos e outros estratégicos são um activo fulcral na afirmação geopolítica de Angola. Importa, contudo, feita a análise das vulnerabilidades tecnológicas, dar início a um processo de longo-prazo, visando uma aposta na introdução das tecnologias de comunicação e da informação, que a prazo poderá permitir a Angola competir com a África do Sul. O sector da agro-indústria é outra aposta estratégica, no quadro de uma auto-suficiência alimentar. Estudos prospectivos apontam para a dependência total de vários países ocidentais, das importações de alimentos para prover a subsistência das suas populações. A título de exemplo refira-se que a Ucrânia, o celeiro da ex-URSS, tem já um plano de investimento agrícola para os próximos 50 anos virado para o abastecimento da Europa.

g) Educativos. Qualquer estratégia de afirmação geopolítica requer um forte investimento na formação de uma elite académica e científica - epistemic community, que funcione como factor radial nos processos comunicacionais de afirmação de Angola. A estratégia para a valorização dos recursos humanos encontra, nos domínios da educação, da ciência e da investigação e desenvolvimento, um campo que é de importância vital melhorar, tirando partido das qualidades intrínsecas dos povos de Angola e dos meios disponíveis. Todas as teorias geopolíticas apontam para a variável educacional e científica como central na projecção de poder dos Estados. As universidades de Angola, melhorando a formação que disponibilizam e intensificando os seus laços internacionais, deverão estar na linha da frente da modernização do país e na sua colocação como uma plataforma regional de recursos humanos altamente qualificados em boa articulação com os seus colegas e instituições académicas de excelência no exterior.

h) Militares. A projecção de poder latente e manifesto das Forças Armadas Angolanas (FAA) constitui por si só um factor central na elaboração de uma estratégia geopolítica. A participação de efectivos das FAA em operações de peace keeping em ambiente de 
conflitos regionais constitui um asset que deverá ser explorado na concepção e execução de uma estratégia comunicacional de imagem geopolítica a larga escala.

\section{Conclusões}

Uma síntese dos pontos axiais do discurso proferido em 12 de Novembro de 2014, pelo ministro angolano das Relações Exteriores, Georges Rebelo Pinto Chikoti (2010), durante a Cerimónia do Dia do Diplomata Angolano, ${ }^{\mathbf{3 5}}$ serve plenamente para concluir o presente artigo.

Com efeito, a Política Externa Angolana sempre foi parte integrante da agenda do seu Governo para defender e promover os interesses dos angolanos, designadamente, a paz, a unidade, a estabilidade, o desenvolvimento/prosperidade e a liberdade.

Sob a liderança de José Eduardo dos Santos, primeiro ministro das Relações Exteriores em $1975,{ }^{36}$ (no âmbito da formação do primeiro Governo da então República Popular de Angola, hoje Presidente da República, por conseguinte, Chefe de Estado, Titular do Poder Executivo e Comandante em Chefe das Forças Armadas Angolanas), o Ministério das Relações Exteriores assumiu o pesado e nobre encargo de contribuir para a consolidação do próprio Estado e a defesa da soberania nacional, afirmando-se, assim, como vanguarda na inserção de Angola no contexto internacional, particularmente em África, nas grandes potências, em organizações internacionais de todo o tipo.

Desde que ascendeu a independência Nacional, em 11 de Novembro de 1975, Angola estabeleceu relações diplomáticas e abriu representações, e reforçou outras, em vários países como forma de defender os seus interesses nacionais e projectar a sua influência na arena internacional. Com a conquista da paz, em 4 Abril de 2002, os

35 Em 29 de Junho de 2011, foi instituída, pelo Conselho de Ministros, a data de 12 de Novembro como Dia do Diplomata Angolano.

36 Lista dos titulares da pasta de Ministro das Relações Exteriores, nos sucessivos governos da República de Angola, no período de 1975 a 2010: José Eduardo dos Santos (1975-1976); Paulo Teixeira Jorge (1976-1984); Afonso Van-Dúnem «Mbinda» (1985-1989); Pedro de Castro Van-Dúnem «Loy» (1989-1992); Venâncio da Silva de Moura (1992-1999); João Bernardo de Miranda (1999-2008); Assunção Afonso de Sousa dos Anjos (2008-2010). 
êxitos conseguidos no processo de reconciliação nacional e de consolidação da democracia, o crescimento impetuoso que o país tem estado a viver nos últimos anos, os passos importantes que têm sido dados na solução dos problemas mais importantes das populações, fazem com que Angola seja vista como um País forte, sério e respeitado pela comunidade internacional.

Com efeito, Angola define-se e tem-se assumido como um Estado Progressista em todo o processo de transformações que ocorrem nas relações internacionais e a sua política externa tem-se baseado nos princípios do respeito e igualdade jurídica entre os Estados, de resolução pacífica dos conflitos, de cooperação entre os povos, de progresso e de justiça social. A estratégia político-diplomática seguida tem sido a de promover não só uma inserção competitiva de Angola no contexto internacional como, também, a de tirar os maiores benefícios da cooperação internacional de modo a elevar sempre, e cada vez mais, a qualidade de vida do Povo Angolano.

Sem dúvida, Angola tem exercido um papel importante no processo de pacificação em África, em particular nas regiões onde está inserida, nomeadamente, SADC, CEEAC, CGG e CIRGL. A Experiência de Angola em contribuir para identificação mais eficiente das causas dos conflitos e eliminação do espectro da violência através da diplomacia preventiva, promover a agenda africana de 2063 e contribuir para a realização da Paz e Segurança no Continente e noutras regiões do mundo, garantiu a sua reeleição, em 16 de Outubro de 2014, a Membro Não Permanente do cs das Nações Unidas, pela segunda vez, sendo a primeira ocorrida em 2002.

Angola sempre procurou apoiar as iniciativas das Nações Unidas e das Organizações regionais no Combate ao Crime Organizado e Transnacional e, terrorismo internacional, reforçando os mecanismos internacionais para a prevenção e mediação de conflitos. ${ }^{37} \mathrm{~A}$ resignação a guerra é uma estratégia que coloca Angola, pela sua experiência, como Nação e na resolução pacífica de conflitos, como uma placa giratória da Diplomacia em África.

Referimo-nos também, do desenvolvimento de uma política de diplomacia da paz, através do mecanismo de prevenção e resolução

37 Para aprofundar a matéria sobre o terrorismo e as estratégias para o seu combate, recomenda-se a obra fundacional sobre $O$ terrorismo transnacional, publicada em Angola (cf. BЕмве 2012). 
de conflitos, pela via do diálogo, da concertação e promoção da cooperação bilateral com os países vizinhos, e multilateral com estes e com os outros, baseado nos princípios da igualdade, das vantagens recíprocas e do respeito pela soberania, nos sectores de economia real visando apoiar a estratégia de diversificação da economia nacional.

\section{Referências bibliográficas}

\section{BEMBE M. D.}

2012, O terrorismo transnacional: Sistematização do fenómeno e estratégias para o seu combate. Luanda, Edição do Autor.

2013a, A questão de Cabinda: Uma visão estratégica. Evolução da situação e cenários de futuro. Luanda, Edição do Autor.

2013b, «Os vectores da construção da Nação Angolana e a função do Estado», Mulemba - Revista Angolana de Ciências Sociais (Luanda), vol. III, n. ${ }^{\circ}$ 6, Novembro, pp. 167-183.

2014, Mecanismos de partilha do poder e acomodação das Elites: Modelo e processo para o Enclave de Cabinda. Lisboa, Instituto Superior de Ciências Sociais e Políticas, Universidade de Lisboa [«Estudos políticos e sociais»].

\section{Bessa A. M.}

2001 (1. ${ }^{\mathrm{a}}$ edição), O olhar de Leviathan: Uma introdução à Política Externa dos Estados Modernos. Lisboa, Instituto Superior de Ciências Sociais e Políticas, Universidade Técnica de Lisboa. 2012 (2. ${ }^{\text {a }}$ edição, revista e ampliada), O olhar de Leviathan: Uma introdução à Política Externa dos Estados Modernos. Lisboa, Universidade Autónoma de Lisboa.

Calvet de Magalhães J., ver Magalhães José Calvet de, infra

Chiкоті G. R. P.

2014, Discurso proferido na Cerimónia do Dia do Diplomata Angolano, em Luanda, 12 de Novembro. Disponível em <http:// www.mirex.gov.ao/Layout/componente/ajax/buscaPublicacao.a spx? content $=\% \%>$, consultado e 5 de Maio de2015, às 18ho8m45s.

Couto A. C.

1988, Elementos de estratégia: Apontamentos para um curso, vol. 1. Lisboa, Instituto de Altos Estudos Militares.

EduARdo dos Santos José, ver Santos José Eduardo dos, infra FERNANDES A. J.

1998, Relações internacionais contemporâneas. Do mundo da Europa à Europa do mundo. Santa Catarina, Editora da Univali. 
Francisco A. A. C.

2013, A política externa de Angola durante a Guerra Fria (1975-1992). Dissertação de Mestrado em Relações Internacionais, na área de Política Internacional e Comparada, Brasília, IRI-Universidade de Brasília.

Gray C. S.

1986, Maritime strategy, geopolitics and the defense of the West. Washington (DC), The National Strategy Information Center, Ramapo Press.

\section{GuEdEs Armando Marques}

2011, "As constantes emergentes e a atipicidade das linhas de força na Política Externa de Angola, 1975-2002», in José Francisco Pavia (ed.), A Política Externa de Angola no novo contexto internacional. Lisboa, Quid Juris?, pp. 21-73.

José J.

2009, «Política externa deAngola de 1992 aos dias actuais». Disponível em <http://portal.anpocs.org/portal/index.php?option=com docman\&task=doc_view\&gid $=1977 \& I t e m i d=229>$, consultado em 14 de Abril de 2015, às 18ho9moos.

Pegado A. M. S. P.

2013, Angola como potência regional emergente: Análise dos factores estratégicos (2002-2012). Tese de doutoramento em Estudos Africanos na especialidade de Desenvolvimento social e económico em África, análise e gestão. Lisboa, ISCTE - Instituto Superior de Ciências do Trabalho e da Empresa / IUL - Instituto Universitário de Lisboa.

Magalhães José Calvet de 2005 (1. ${ }^{\mathrm{a}}$ edição), A diplomacia pura. Lisboa, Editorial Bizâncio.

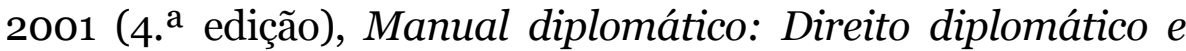
prática diplomática. Lisboa, Editorial Bizâncio.

Pureza J. M., et al.

2007, «As novas operações de paz das Nações Unidas. Os casos de Angola, Timor Leste e Moçambique». Coimbra, Oficina do Centro de Estudos Sociais, n. ${ }^{\circ}$ 290. Disponível em < http://www.ces. uc.pt/publicacoes/oficina/ficheiros/290.pdf >, consultado em 4 de Abril de 2015, às 20h6m44s.

QueIroz Magalhães

1994, «O carácter multidisciplinar da Defesa Nacional e a articulação interministerial», Nação e Defesa (Lisboa), Instituto da Defesa Nacional, Ano XIX, n. ${ }^{\circ}$ 71, Julho-Setembro, pp. 29-44.

ROMANA H.

2012, "Apontamentos das aulas de geopolítica e geostratégia», 
Programa de doutoramento em Estudos Estratégicos do ISCSP, ano lectivo 2012-2013. Lisboa, ISCSP - Instituto Superior de Ciências Sociais e Políticas, Universidade de Lisboa.

SANTOS José Eduardo dos

2014, "Presidente da República exorta empresários franceses a investirem na República de Angola». Discurso proferido em Paris no dia 29 de Abril de 2014. disponível em <http://m.portalangop.co.ao/angola/pt_pt/mobile/noticias/politica/2014/3/18/ Franca-Presidente-Republica-exorta-empresarios-francesesinvestirem-Angola,799f915d-6d53-4169-beef-oaee2e6ade20. html?version $=$ mobile $>$, consultado em 05 de Abril de 2015, às 07h21m.

SAntos V. M. dos

2000, Reflexões sobre a problemática da avaliação de resultados em política externa. Lisboa, ISCSP - Instituto Superior de Ciências Sociais e Políticas, Universidade Técnica de Lisboa [policopiado]. 2012, Elementos de Análise de Política Externa. Lisboa: ISCSP Instituto Superior de Ciências Sociais e Políticas, Universidade de Lisboa [«Manuais pedagógicos»].

SiLVA S. V. da

2012, "A intervenção cubana em Angola revisitada», ResPublica - Revista Lusófona de Ciência Política e Relações Internacionais (Lisboa), n. ${ }^{\circ}$ 12, Universidade Lusófona de Humanidades e Tecnologias, pp. 69-104.

Veríssimo G. P.

2014, A posição estratégica de Angola no Golfo da Guiné. Contributo para as políticas externa e de defesa. Tese de doutoramento em Estudos Estratégicos. Lisboa, ISCSP - Instituto Superior de Ciências Sociais e Políticas, Universidade de Lisboa.

Recepção do manuscrito: 03/04/2016

Conclusão da revisão: 15/06/2016

Aceite para publicação: 30/06/2016

Title: The Angolan Foreign Policy: Doctrine and Practice

Abstract: The Angolan Foreign Policy is an almost unknown area and even less investigated. As a reflection of the State's ability to adapt to the environment in which it operates, the Foreign Policy Review is crucial in trying to understand the decisions and actions governments take - or are obliged to take - in order to preserve the positive aspects of International environment and to explore the possibility of changing its negative aspects. This article, far from 
wanting to fill the announced gap, intends to analyze and characterize, in a political and internationalist analytical perspective, the fundamental moments of the Angolan Foreign Policy, more specifically, the main lines of force and trends of its evolution from 1975 to the present time. Thus, the process of its elaboration sought to correspond to the basic and specific need of the expository adaptation to a schematic functionality of approach, which does not aim at an in-depth analytical purpose of the time interval to which it pays exclusive attention.

Keywords: Angola, foreign policy, transformations, trends of evolution.

\section{Miguel Domingos Bembe}

É Doutor e Mestre em Ciências Sociais, respectivamente, na especialidade de Ciência Política (13 de Maio de 2014) e Estratégia (31 de Março de 2009) pelo Instituto Superior de Ciências Sociais e Políticas da Universidade de Lisboa, em Portugal. É Conselheiro do Quadro de Pessoal da Carreira Diplomática do Ministério das Relações Exteriores (MIREX) da República de Angola. Exerce as funções de Consultor no Gabinete do Ministro das Relações Exteriores (GMRE) e de Professor Auxiliar no Departamento de Ciência Política da Faculdade de Ciências Sociais (FCS) da Universidade Agostinho Neto (UAN), onde lecciona Análise Política I e II (Perspectivas Interna e Externa); Geopolítica e Geoestratégia; Políticas de Defesa e Segurança Nacional; Cultura Estratégica Angolana; Informações e Segurança; e, Teoria e Prática da Democracia.

Possui várias obras e artigos científicos publicados, com destaque para: Mecanismos de partilha do poder e acomodação das elites. Modelo e processo para o Enclave de Cabinda. Lisboa, Instituto Superior de Ciências Sociais e Políticas, 2014 [«Estudos políticos e sociais»]; $A$ questão de Cabinda: Uma visão estratégica. Luanda, Edição de Autor, 2013; O terrorismo transnacional. Estratégias para o seu combate. Luanda, Edição de Autor, 2012; O estudo científico da Ciência Política. Abordagens epistemológicas e metodológicas, Luanda, Edições Mulemba; Mangualde, Edições Pedago, 2013 [em co-autoria com Paulo Faria e Fernando Muquepe]; «Os vectores da construção da "Nação-angolana" e a função do Estado", Mulemba - Revista Angolana de Ciências Sociais (Luanda), vol. III, n. ${ }^{\circ}$ 6, Novembro de 2013, pp. 167-183; «Poder local e democracia em Angola. Oportunidades e desafios», Mulemba - Revista Angolana de Ciências Sociais (Luanda), vol. II, n. ${ }^{\circ}$ 3, Maio de 2012, pp. 35-57; «O Estado e o poder tradicional em Angola», Mulemba - Revista Angolana de Ciências Sociais (Luanda), vol. I, n. ${ }^{\circ}$ 2, Outubro de 2011, pp. 9-27.

[e-mail: miguelbembe@fcs.uan.ao

[e-mail: miguelbembe@gmail.com] 